\title{
High-generation near-isogenic lines combined with multi-omics to study the mechanism of polima cytoplasmic male sterility
}

Benqi Wang, Zunaira Farooq, Lei Chu, Jie Liu, Huadong Wang, Jian Guo, Jinxing Tu, Chaozhi Ma, Cheng Dai, Jin Wen, Jinxiong Shen, Tingdong Fu and Bin Yi

\begin{abstract}
Background: Cytoplasmic male sterility (CMS), which naturally exists in higher plants, is a useful mechanism for analyzing nuclear and mitochondrial genome functions and identifying the role of mitochondrial genes in the plant growth and development. Polima ( $p o l)$ CMS is the most universally valued male sterility type in oil-seed rape. Previous studies have described the pol CMS restorer gene Rfp and the sterility-inducing gene orf224 in oil-seed rape, located in mitochondria. However, the mechanism of fertility restoration and infertility remains unknown. Moreover, it is still unknown how the fecundity restorer gene interferes with the sterility gene, provokes the sterility gene to lose its function, and leads to fertility restoration.

Result: In this study, we used multi-omics joint analysis to discover candidate genes that interact with the sterility gene orf224 and the restorer gene Rfp of pol CMS to provide theoretical support for the occurrence and restoration mechanisms of sterility. Via multi-omics analysis, we screened 24 differential genes encoding proteins related to RNA editing, respiratory electron transport chain, anther development, energy transport, tapetum development, and oxidative phosphorylation. Using a yeast two-hybrid assay, we obtained a total of seven Rfp interaction proteins, with orf224 protein covering five interaction proteins.

Conclusions: We propose that $R f p$ and its interacting protein cleave the transcript of atp6/orf224, causing the infertility gene to lose its function and restore fertility. When Rfp is not cleaved, orf224 poisons the tapetum cells and anther development-related proteins, resulting in pol CMS mitochondrial dysfunction and male infertility. The data from the joint analysis of multiple omics provided information on pol CMS's potential molecular mechanism and will help breed B. napus hybrids.
\end{abstract}

Keywords: Polima, CMS, Multi-omics analysis, Brassica napus, orf224, Rfp

\footnotetext{
*Correspondence: yibin@mail.hzau.edu.cn

National Key Laboratory of Crop Genetic Improvement, National Center of Rapeseed Improvement, Huazhong Agricultural University, Wuhan 430070, China
}

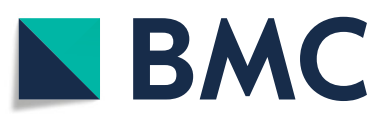

() The Author(s). 2021 Open Access This article is licensed under a Creative Commons Attribution 4.0 International License, which permits use, sharing, adaptation, distribution and reproduction in any medium or format, as long as you give appropriate credit to the original author(s) and the source, provide a link to the Creative Commons licence, and indicate if changes were made. The images or other third party material in this article are included in the article's Creative Commons licence, unless indicated otherwise in a credit line to the material. If material is not included in the article's Creative Commons licence and your intended use is not permitted by statutory regulation or exceeds the permitted use, you will need to obtain permission directly from the copyright holder. To view a copy of this licence, visit http://creativecommons.org/licenses/by/4.0/. The Creative Commons Public Domain Dedication waiver (http://creativecommons.org/publicdomain/zero/1.0/) applies to the data made available in this article, unless otherwise stated in a credit line to the data. 


\section{Background}

Cytoplasmic male sterility (CMS) refers to plants' inability to yield functional pollen, and this natural occurrence is widespread in vascular plants, specifically in flowering plants [1]. Researchers use CMS to adequately breed crops for hybrid seed production, which is a highly effective approach to use heterosis [2]. CMS appears to be mainly caused by rearrangements, deletions, or mutations of genes located in mitochondria, which can be eliminated by the fertility restoration factor genes present in the nuclear genome [3, 4]. CMS not only can be used to study the relationship between cytoplasmic genes and nuclear genes but can also be a suitable donor for examining heterosis, providing a theoretical basis for three-line breeding $[5,6]$. As researchers continue to elucidate the factors that lead to abnormal pollen development, several factors can cause this phenomenon to be discovered. Scientists have made corresponding assumptions regarding CMS mechanisms, such as cytotoxicity, advanced programmed cell death (PCD), energy deficit, and reverse inverse regulation hypotheses [7]. Although there is no direct evidence to prove the toxic protein hypothesis, the fertility suppression effect of sterility genes on prokaryotic cells has been well documented [8-10]. Rearrangement of mitochondrial genes leads to energy loss, which might be a significant reason for anther abortion in CMS [11]. Previous studies have shown that during the CMS-T of maize, the mitochondria split rapidly during anther development. Therefore, elevated expression of CMS genes might cause mitochondrial function defects, resulting in insufficient energy supply for male organ development, thus triggering abortion [12]. ATP synthesis requires the flow of hydrogen ions generated by the concentration gradient of hydrogen ions produced by complex I, II, III, and IV in the mitochondria, and the integrity of the mitochondrial membrane structure is crucial to the generation of ATP [[11, 13]]. Many proteins encoded by CMS genes, including URF13, ORF138, ORF79, and ORPH79, are transmembrane proteins. These proteins may bind to the mitochondrial inner membrane, affecting the hydrogen ion concentration gradient, thus affecting ATP synthesis [14-16].

Oil-seed rape (Brassica napus L.) is the fourth-largest oil-producing crop worldwide. The cytoplasmic male sterility of Brassica napus has also been extensively studied as a rich source of cytoplasmic male sterility promoting hybrid seed production for the desirable traits. Previous studies found that there are at least nine types of CMS in rapeseed: ogu CMS [17], nap CMS [18], Tour CMS [19], pol CMS [20], shan2A CMS [21], oxa CMS [22], Nca CMS [23], Moricandia arvensis CMS [20], Nsa CMS [24], hau CMS [25], inap CMS [25]. CMS is classified into sporophytic and gametophytic sterility according to the period of anther abortion. In rapeseed, the currently reported type of sterile cytoplasm is sporophytic sterility. According to the cytoplasm source, CMS is branched into two types: homogeneous cytoplasm and heterogeneous cytoplasmic sterility [26].

In rapeseed, the most familiar type of CMS is pol CMS, which is used worldwide for research purposes. Since its discovery in 1987, it has been found that abnormal transcription of the mitochondrial gene orf224/atp6 leads to the occurrence of pol CMS [27], but how the sterility gene orf224 contributes to the development of abnormal anther functioning remains to be explored [28]. Besides, the restoration gene of pol CMS has been verified by map-based cloning [29-31]. $R f p$ (fertility-restorer) is a nuclear gene encoding a PPR protein located in mitochondria, and it ultimately leads to the malfunctioning of the sterility gene orf224, thus allowing restoration of pol CMS-induced fecundity [29]. However, the mechanism of fertility restorer is not scrutinized. Anther examination in B. napus showed that some proteins' cumulative levels fluctuate considerably, including proteins related to energy and carbohydrate metabolisms, photosynthesis and flavonoid production, aldehyde dehydrogenase performance, and cell wall remodeling [32]. CMS's occurrence is characterized by considerable differences in protein level, transcription level, and metabolic level. We will further analyze CMS's causes and results through the combined analysis of proteomes, transcriptomes, and metabolomes to provide a new research basis for elucidating nuclear-plasmid interfaces. The discovery of new types of CMS may not only improve the cytoplasmic resources of cruciferous plants but also provide valuable resources for examining nuclearplasmid interaction [11, 33]. In the development of multi-omics, nucleomics (including genomics and transcriptomics) reveal the underlying factors of life phenomena, proteomics reveals the external factors of life phenomena, and metabolomics reveals the final results phenomena. Therefore, by integrating the results of different monolayers of histology to realize the deeper excavation of the essence of life phenomena from cause to effect and from the surface to inward, we will have a more comprehensive and accurate understanding of the laws that reveal the characteristics of life [[34, 35]].

RNA is a genetic macromolecule that plays numerous roles in eukaryotes and prokaryotes. RNA has three types, which have different locations and functions within the cell during an organism's lifecycle Messenger RNA (mRNA), Ribosomal RNA (rRNA), and transfer RNA (tRNA). RNA is a significant element of ribozymes and riboproteins. The 
microdissection technique for isolating specific materials is required for gene expression profiling and has become a popular research area. Unlike singlecelled organisms, higher plants have evolved into too complex organisms; they are categorized based on the essential functions performed by well-maintained organs and tissues. Current researchers ignore this point that plants have different cell types; therefore, their experimental results have not been in-depth or informative. Analysis of overall transcription levels with a high spatial resolution is mandatory to describe specific tissues' status entirely. Therefore, differences in gene transcription at the single-cell level that occur in specialized plant cells are crucial for analyzing the mechanism of plant trait occurrence, and these differences have also sparked widespread interest among scientists [36]. Laser capture microdissection, laser microdissection, and pressure ejection are suitable sampling techniques for collecting homogeneous cells to analyze plant metabolites. Tapetum cells were excised by microdissection, and RNA was extracted and amplified to perform singlecell transcriptome sequencing. In the present study, we applied a multi-omics joint analysis to discover candidate genes that interact with the sterility gene orf 224 and the restorer gene $R f p$ of pol CMS to provide theoretical support for the occurrence and restoration mechanisms of sterility.

\section{Results}

Observation of micromorphological defects of pollen CMS in Brassica napus

We used the sterile line 1141A of pol CMS and the restoring line material bing409. After 13 generations of backcrossing, we constructed the NIL material of the restoration gene of pol CMS. There was no phenotypic difference between the sterile line and the restorer line throughout the asexual development period. However, in the later period of the restorer growth, the pol CMS's flower buds and flowers' morphology differed significantly. After stereomicroscopy and scanning electron microscopy observation of the difference between the anther and pollen of the sterile line and restorer line, we found a considerable difference in pollen between the sterile and restorer lines. In the sterile line, the buds and stamens were dried up, the petals became smaller and contracted, and there was no pollen and significantly less nectary (Fig. $1 \mathrm{~A}$ and C).

In contrast, the restored plant was healthy, showing a wild-type petal and stamen growth with a maximum amount of nectary (Fig. $1 \mathrm{~B}$ and D). Comparison of sterile-line pollen with restorer-line pollen via scanning electron microscopy revealed many abnormal developmental protrusions (Fig. $1 \mathrm{E}$ and F), anther epidermal growth retardation (Fig. $1 \mathrm{G}$ and $\mathrm{H}$ ) with pollen grains present on the surface, and abnormal shrinkage rupture

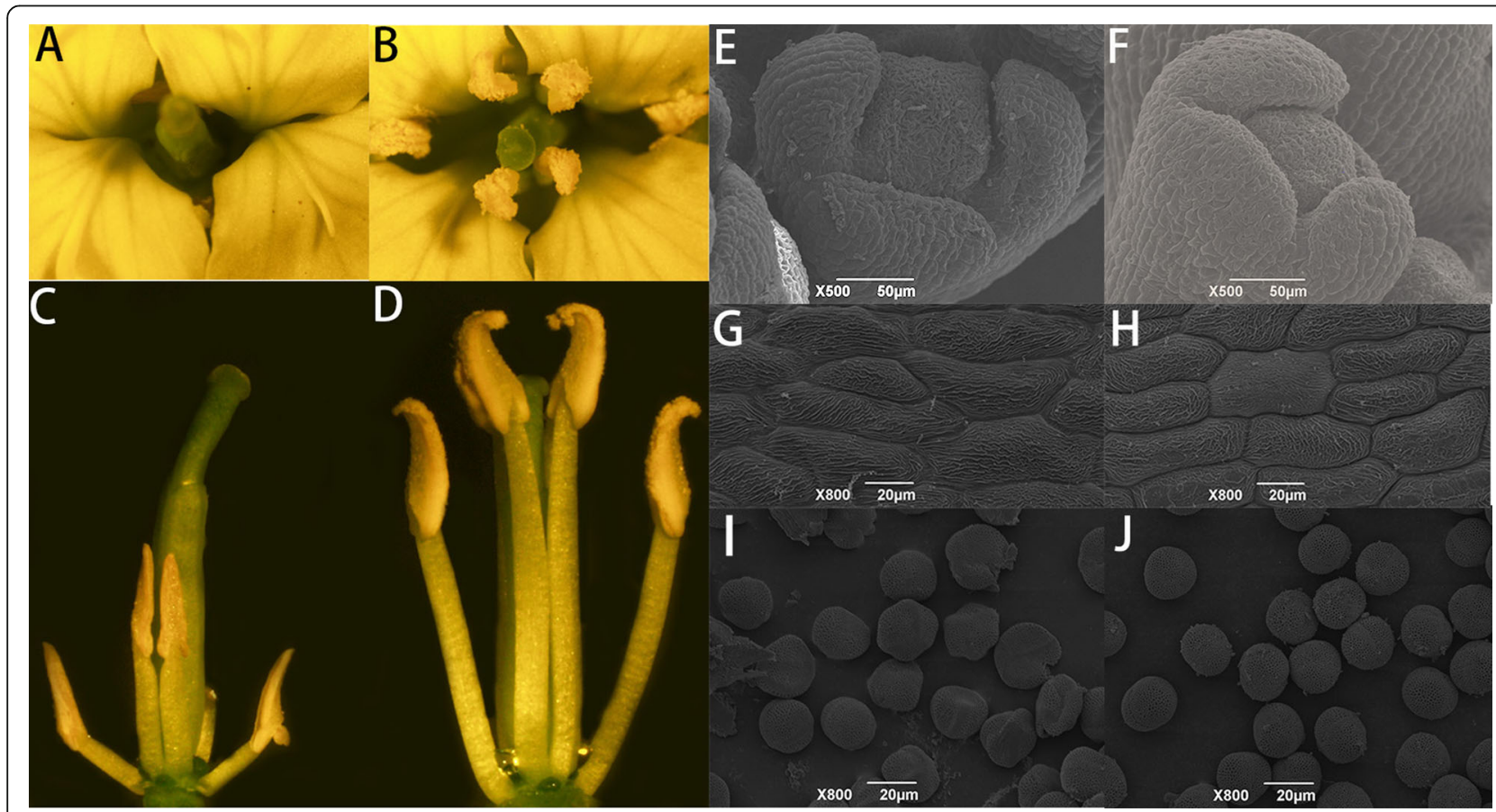

Fig. 1 Stereomicroscopy and scanning electron microscopy analyses of differences in anther development and pollen development in sterile and reintroduction materials. $(A, C, E, G, I)$ pol CMS sterile plants anthers, flower buds, and pollen grains in the corresponding period. $(B, D, F, H, J)$ pol CMS recultivated plant stamens mature anthers, flower buds, pollen grains during differentiation 
(Fig. $1 \mathrm{I}$ and J). The pollen grains of sterile plants shrank markedly, bent inward, and collapsed; moreover, the outer wall development was abandoned, and the central plate was irregular.

\section{Analysis of anther metabolites in sterile and restorer lines of pol CMS near-isogenic lines}

Metabolic analysis of the flower buds of sterile and restorer lines of pol CMS near-isogenic lines identified 699 metabolites, including 88 amino acids derivatives, 71 phenylpropanoids, 17 alcohols, 10 polyphenols, 26 phenol amides, 57 nucleotide derivatives, 8 anthocyanins, 41 flavones, 25 flavonols, 17 flavonoids, 14 flavanones, three quinones, 32 alkaloids, 21 carbohydrates, 17 terpenes, 3 vitamins and derivatives, four isoflavone, 8 indole derivatives, 110 organic acids and derivatives, one proanthocyanidin, six steroids, 65 lipids, and 35 others (Fig. 2a). Principal component analysis (PCA) showed that the abundance of the metabolites in the flower buds of sterile and restorer lines of pol CMS changed tremendously, and the sterile and fertile were well separated, with the largest reaching $23.39 \%$ and the groups reaching 36.36\% (Fig. 2b).

In this study, by using heat map clustering, we classified the metabolites of the sterile and restorer lines (Fig. S1A). KEGG enrichment analysis showed that the metabolites were involved in secondary metabolism, flavonoid metabolism, and glycolysis/gluconeogenesis pathways, as the metabolite levels changed remarkably in these pathways (Fig. S1B; Table S1). A volcano plot of differential metabolites showed 37 metabolite differences (|Fold change $\mid \geq$ one and $\mid$ Fold change $\mid \leq 0.5$ ) between the sterile and restorer lines and 11 kinds of flower buds in the sterile line compared with those in the restorer line. Moreover, there were 11 up-accumulated and 26 downaccumulated metabolites (Fig. 3a). Figure $3 \mathrm{~b}$ lists the top 20 substances with multiple metabolite differences, with pterostilbene being the most upaccumulated and D-erythro-sphinganine being the most down-accumulated (Table S4).

\section{Differentially abundant proteins (DAPs) between the sterile and restorer lines of $\mathrm{pol}$ CMS}

To further explore the mechanism of pol CMS in the sterile and restorer lines, we sampled the flower buds of B. napus $<0.5 \mathrm{~mm}$ to determine the proteomes, and we used a label-free method to detect the gene expression differences and protein abundance differences between sterile and restorer lines of near-isogenic lines. For proteomes, 711,479 total spectra, 27,274 matched spectra, 46,998 peptides, 30,391 unique peptides, 7598 proteins, and 4967 quantifiable proteins were detected (Fig. S2A, C). PCA analysis results showed that among the sterile and restorer lines, the difference between the groups was significant at $44.6 \%$, and the difference within the group was $14.9 \%$, which can better distinguish the differences between the two materials and indicates that the method has good quantitative repeatability (Fig. S2B).

The label-free method was used to detect proteins at four levels. Based on $-\log 10 P$-value $>1.5,140$ DAPs were identified. Among these proteins, 65 were upaccumulated, and 75 were down-accumulated (Fig. S2D). COG/KOG classification analysis showed that DAPs were divided into 18 functional (Fig. 4). COG/KOG functional analysis of differentially expressed proteins showed that metabolic processes with considerable differences involved post-translational modification, protein turnover, chaperones, translation, ribosomal structure

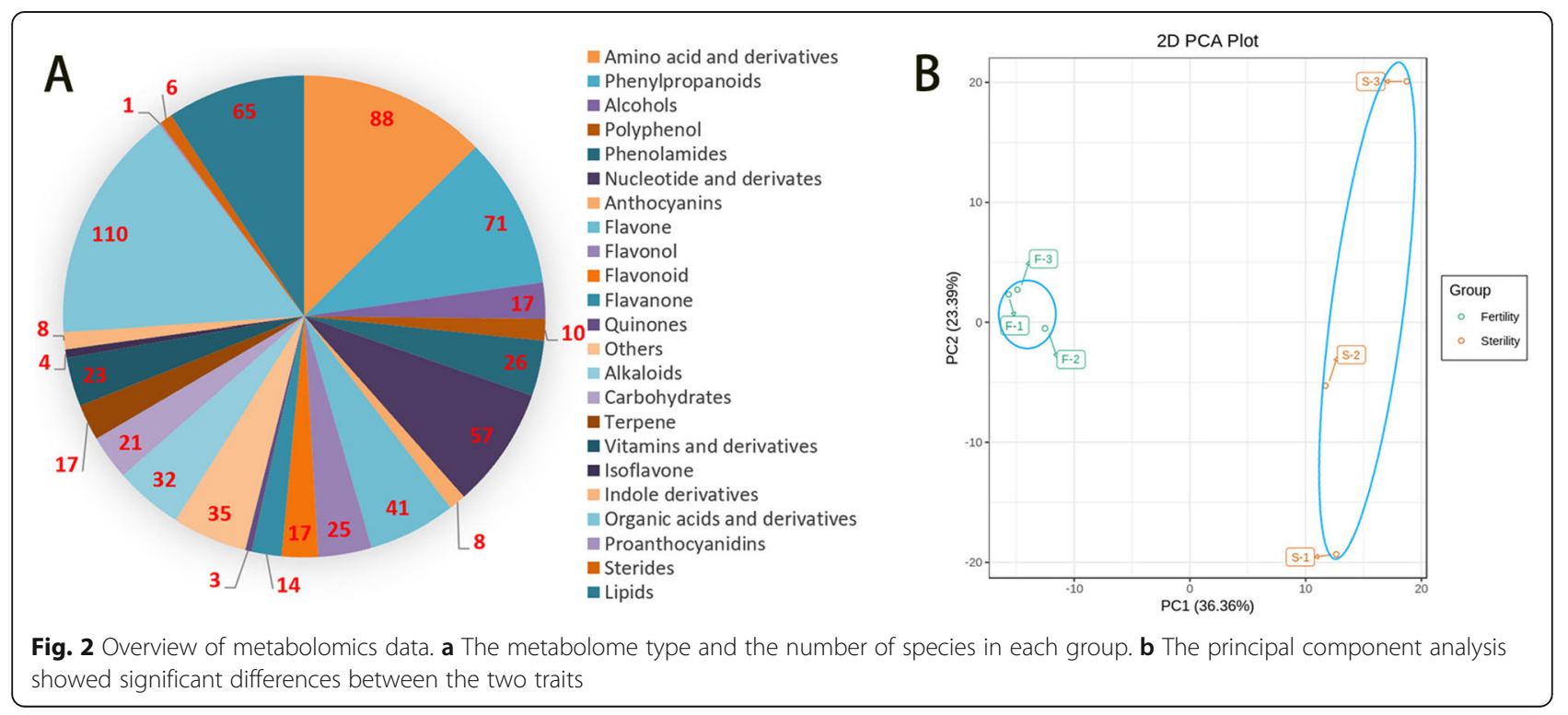



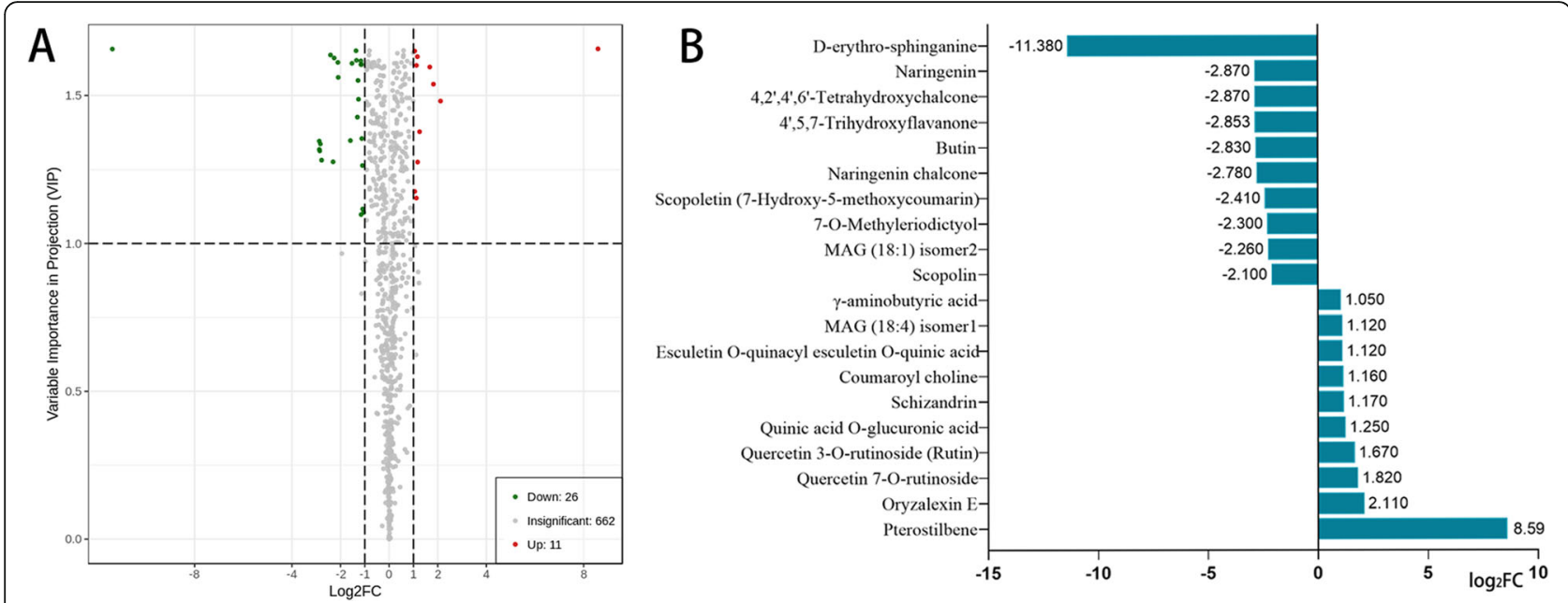

Fig. 3 Differences in metabolites between sterile and restorer lines in the metabolome. a Volcano plot of differential metabolites of the metabolome. $\mathbf{b}$ Histogram of the top 20 substances in the differential metabolites of the metabolome

and biogenesis, and energy production and conversion (Table S3, S5). Through previous studies, it is found that pol CMS's occurrence mainly occurs at the beginning of the fourth stage of anther development. The tapetum layer is caused by programmed death in advance, and the tapetum layer mainly provides energy for the development of anthers.

Simultaneously, the cytoplasmic male Sterility also occurs mainly in mitochondria, and mitochondria are also used as a place for energy conversion in plant development. Therefore, we speculate that the occurrence of pol CMS may be related to the production and conversion of energy, thereby regulating the degradation of tapetum and triggering the development of anthers abnormal." We performed GO analysis to determine the functional group of DAPs. The 140 DAPs between the CMS and the maintenance lines were divided into 17 functional groups, of which biological processes, cellular components, and molecular functions accounted for 7, 4, and 6 GO terms, respectively. For biological processes, there are 30 proteins in protein-rich cellular processes, 56 proteins in metabolic processes, 26 proteins related to a single biological process, four responses to stimulus, eight proteins for localization, and three proteins for regulation of the biological process. Besides, genes were restored in cytoplasmic male sterility in transport activation and further aspects of the existing changes. Related proteins involved in the cell cycle and restorer processes showed different pol CMS lines (Table S5). The cell components are disturbed; there are 18 cell component proteins, 11 organelles, 13 biological macromolecular complexes, and 10 Membrane-associated proteins. In the molecular functional group, proteins with catalytic and binding activities accounted for 54 and 49 proteins, respectively, four proteins had transporter active, eight structural molecular active proteins, three antioxidant proteins, and three other characteristic proteins (Fig. 5).

\section{Single-cell transcriptome sequencing of the tapetum of sterile and fertile lines of pol CMS near-isogenic lines}

We used laser microdissection and Illumina technology for single-cell RNA-Seq analysis to clarify the relationship between differentially expressed genes (DEGs) and pol CMS in NILs. After raw data were trimmed, a total of 52,936,673 and 52,606,810 clean reads were obtained for fertile and sterile samples, respectively. Furthermore, the Q20 and Q30 were $>96.61$ and $>92.53 \%$, respectively. The GC content for both sterile and fertile samples was regularly shown to be approximately $45 \%$, signifying that the sequencing was exact. All clean reads $(105,543$, 483) were aligned using the Trinity program, resulting in 117,332 contigs with a mean length of $901 \mathrm{nt}$ (Fig. S3). We performed clustering and identified 80,851 unigenes (> $200 \mathrm{bp}$ ); the average length was $1054 \mathrm{nt}$, and the N50 was $1586 \mathrm{nt}$. The length of all unigenes recorded was longer than $199 \mathrm{bp}$, and $86.95 \%$ of them ranged from 200 to $1999 \mathrm{bp}$. We subjected all assembled unigenes to search against the Nr, Swiss-Prot, and COG databases, and 66,143 (81.81\%), 54,857 (67.85\%), and 28,129 $(34.79 \%)$ unigenes were aligned against these three protein databases, respectively (Fig. S3). Among them, 114, 517 and 104,780 genes were detected in the sterile and restorer line materials, respectively, and 98,735 genes were detected in both materials.

We analyzed DEGs between sterile and restorer lines for advanced recognition of differences in gene expression patterns. We identified 831 genes in the comparison of fertility and infertility, including 501 upregulated 


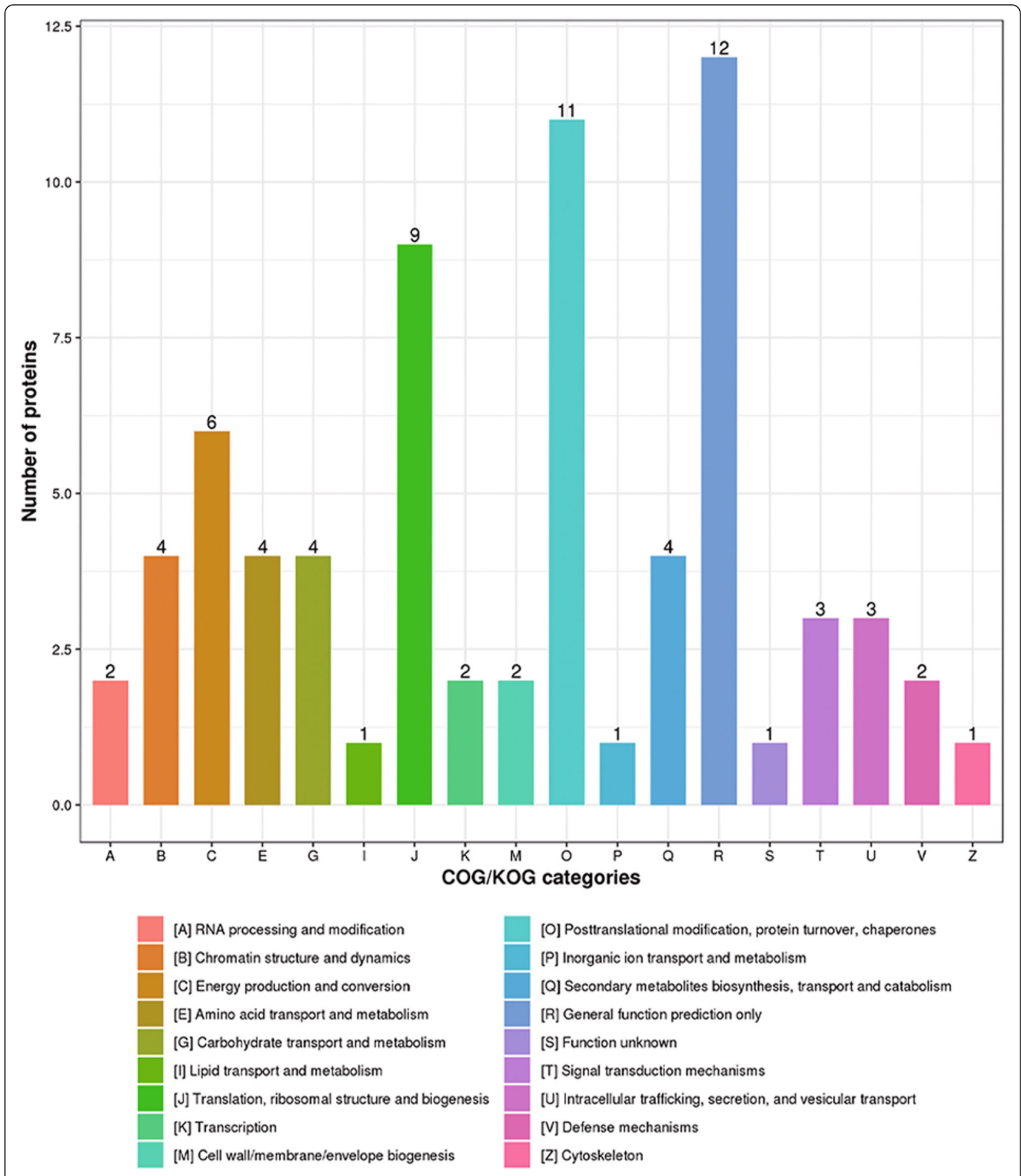

Fig. 4 Differentially abundant proteins (DAPs) between the sterile line and its iso-nuclear maintainer line. Volcano plot of DAPs (fold > 1.5)

genes and 330 downregulated genes (Fig. 6a). The genes with significant differences of FDR $\leq 0.05$ were selected for KEGG enrichment pathway analysis. The results showed enriched genes in Photosynthesis, Photosynthesis-antenna proteins, Carbon fixation in photosynthetic organisms,
Glycolysis/Gluconeogenesis, Starch and sucrose metabolism, Porphyrin and chlorophyll metabolism, Fructose and mannose metabolism, Glycerophospholipid metabolism, and other metabolic pathways (Fig. 6b; Table S2, S6). Anther cells also showed rapid proliferation and vigorous 


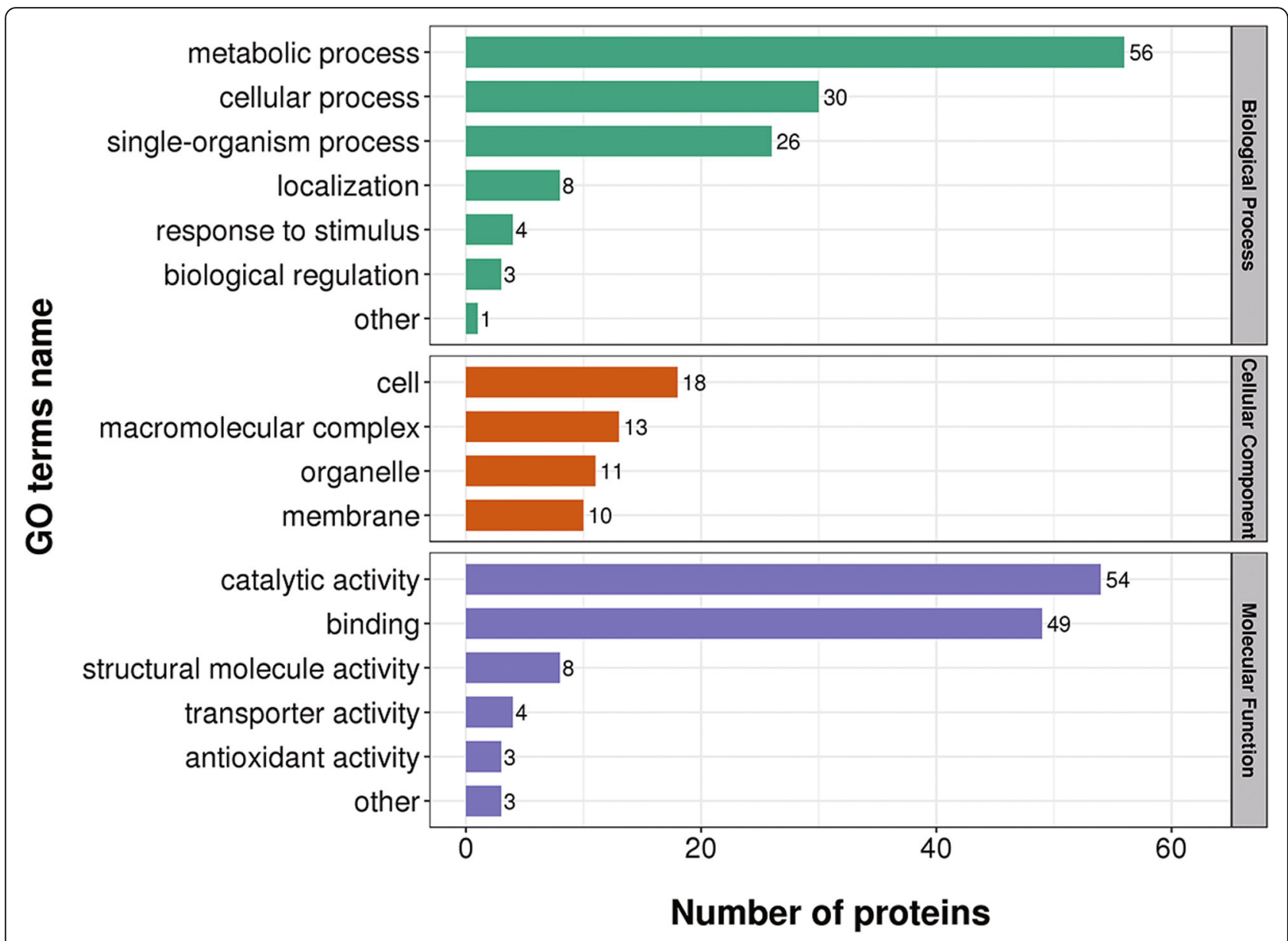

Fig. 5 Gene Ontology $(\mathrm{GO})$ classifications of differentially abundant proteins (DAPs) between the sterile line and its reproductive line. The $x$-axis represents the number of DAP proteins in each category, and the y-axis represents each GO term

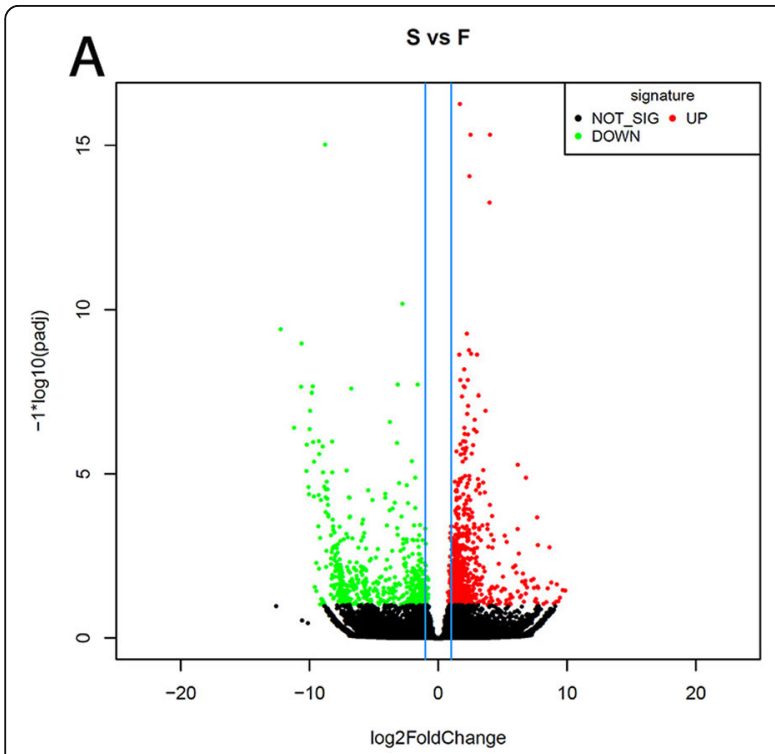

B

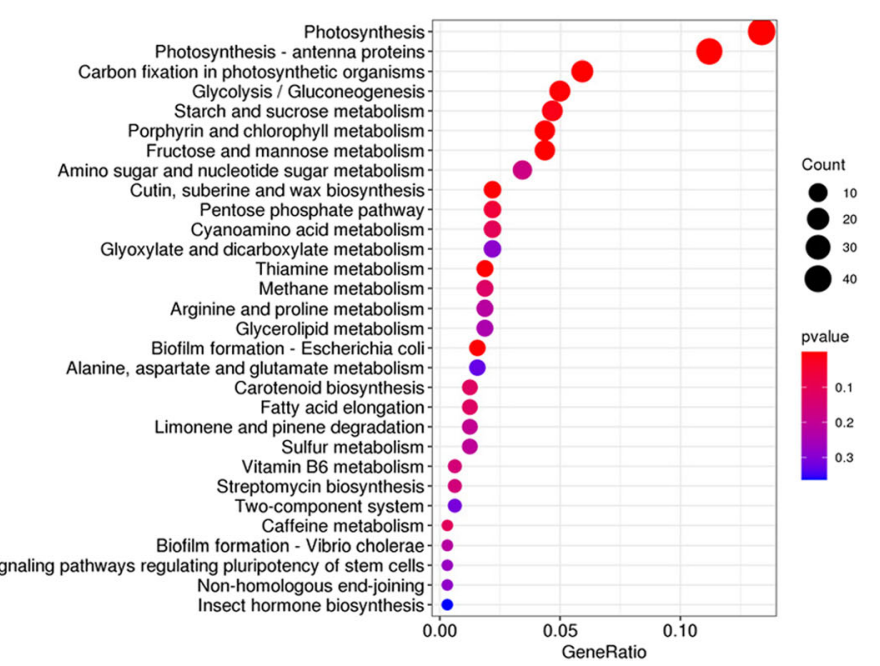

Fig. 6 Transcriptome analysis results. a Volcano plot of the results of transcriptome analysis of significantly differentially expressed gene clusters. $\mathbf{b}$ KEGG pathway functional annotation gene distribution map of significantly differentially expressed genes 
metabolic processes during the growth process [37]. Therefore, the photosynthesis and sugar metabolism processes involved in energy metabolism may play an essential role in developing B. napus anthers.

\section{Combined transcriptome, proteome, and metabolome analysis}

Through the combined analysis of proteomes, metabolomes, and transcriptomes, we found that in the sterile line and restorer line of pol CMS near-isogenic lines, owing to differences in the restoration gene $R f p$, a series of genes and pathways occurred in Brassica rapa. We performed KEGG enrichment analysis on the detected DEGs and metabolites. The joint analysis of proteomes and metabolomes revealed a significant difference in glycolysis/gluconeogenesis and other metabolic pathways. The joint analysis of transcriptomes and metabolomes disclosed significant differences in three pathways: the phenylpropane biosynthesis pathway, glycolysis/gluconeogenesis metabolic pathway, and pyruvate biosynthesis pathway. However, transcriptome and metabolome enrichment analysis presented substantial differences in calcium-transporting ATPase activity, epithiospecifier protein, glycolysis/gluconeogenesis, phosphatase activity, and starch sucrose metabolisms (Fig. S4).

In proteome, metabolome, and transcriptomics analysis, we obtained 141 differential proteins, 37 differential metabolites, and 831 differential genes. By combining the differential genes in the three omics of the proteome, transcriptome, and metabolome in the analysis, a total of 24 genes were screened for associated differences in the proteome, transcriptome, and metabolome. The functions of these genes mainly include genes related to RNA editing, respiratory electron transport chain, anther development protein, energy transportrelated protein, tapetum development protein, and oxidative phosphorylation protein (Table 1). In the highgeneration near-isogenic line materials, the significant differences in restoration genes led to differences in protein, metabolic, and transcription levels. Therefore, we screened for protein interactions between the pol CMS sterility gene orf 224 and the restoration gene $R f p$ by yeast two-hybridization to understand further the mechanisms of sterility and restoration genes (Fig. 7a). RTPCR validated the genes validated by yeast twohybridization, and only three genes were found to be insignificantly different, while all other genes were significantly different (Fig. S5).

Studies have shown that the pathways related to RNA editing, respiratory electron transfer chain, anther development, energy transport, tapetum development, and oxidative phosphorylation involve interactions between infertility genes and restoration genes. We used yeast two-hybrid to find the protein that interacts with the restorer gene to analyze the mechanism by which the restorer genes restore fertility. The results showed that the restorer gene and the protein involved in RNA editing might work together in the pol CMS atp6/orf224 transcript. Mutual work of the restorer gene and the protein involved in RNA editing was shown to induce the infertility gene to be non-functional. We also concluded that restorer genes also interacted with proteins related to energy, respiratory electron transfer chain, and pyruvate dehydrogenase, indicating that the occurrence of CMS and fertility restoration might be strictly associated with energy metabolism.

Similarly, we used the orf 224 protein of the sterility gene to verify the selected candidate genes. Previous studies have found that the sterility gene mainly interacted with pollen development and tapetum-related proteins; thus, we inferred that the sterility gene was mainly related to pollen development. The protein pathway related to tapetum development led to the occurrence of pol CMS. Therefore, considering our results above, we propose a hypothesis to explain the mechanism of pol CMS's occurrence and the role of gene restoration. When the restorer gene is a stealth gene, it will not interfere with the sterile gene's function. Therefore, the orf 224 protein would affect the proteins associated with the development of velvet cells or anther development in B. napus, thus resulting in anther abortion in pol CMS. When the restorer gene is dominant, as the restorer gene $R f p$ cannot directly cut the mRNA transcript, the Rfp gene will bind to the corresponding protein, which together causes the atp6/orf226 transcript to change; this causes orf224 to lose its toxic function, thereby restoring fertility.

\section{Discussion}

With the advancement of science and technology, multiomics analysis is extensively used to solve biological problems [38]. Multi-omics joint analysis can understand and prioritize the problems we need to solve from big data and multi-dimensional data [39]. This study used laser capture microdissection to extract RNA from tapetum cells for transcriptome analysis, and $<1 \mathrm{~mm}$ flower buds were used for proteomics and metabolomics analysis [29]. Excellent results were achieved for our subsequent analysis and screening of candidate genes. We obtained 24 candidate genes involved in RNA editing, electron transfer respiratory chain [16], anther development, energy conversion, tapetum development, and oxidative phosphorylation-associated through joint analysis of multi-omics pathways. Our results suggested that glycolysis/gluconeogenesis pathways were near related to the generation and transport of energy in the tricarboxylic acid cycle [40]. This study's joint analysis found a correlation analysis of glycolysis/ 
Table 1 Screening of differentially expressed genes through joint analysis of multiple omics, followed by Rfp and orf224 for yeast experiment verification

\begin{tabular}{|c|c|c|c|c|c|c|}
\hline \multirow[t]{2}{*}{ Transcription ID } & \multirow{2}{*}{$\begin{array}{l}\text { Protein. } \\
\text { accession }\end{array}$} & \multicolumn{2}{|c|}{ Protein interaction } & \multirow[t]{2}{*}{$\log 2 \mathrm{FC}$} & \multirow[t]{2}{*}{$p$-value } & \multirow[t]{2}{*}{ Description } \\
\hline & & orf224 & $R f p$ & & & \\
\hline \multicolumn{7}{|l|}{ RNA editing protein } \\
\hline BnaA09g06660D & A0A078FUQ6 & + & - & -0.61706 & 0.00150 & RNA recognition motif (RRM)-containing protein \\
\hline BnaC06g23390D & A0A078FDM2 & - & + & -0.23610 & 0.53657 & RNA polymerase II subunit C-terminal domain phosphatase \\
\hline BnaA01g22260D & A0A078GHA1 & - & - & -1.22769 & 0.01624 & RNA-binding protein 25 isoforms $X 1$ \\
\hline \multicolumn{7}{|c|}{ Respiratory electron transport chain protein } \\
\hline BnaA02g35610D & A0A078JFK2 & - & + & -0.79086 & 0.00062 & Electron transfer activity/cupredoxin superfamily protein \\
\hline BnaA05g32320D & A0A078I0S7 & - & + & 0.73948 & 0.16802 & NADH dehydrogenase [ubiquinone] iron-sulfur protein 6 \\
\hline BnaA06g16370D & A0A078F502 & - & - & 0.98176 & -0.00616 & Gamma carbonic anhydrase-like 2 \\
\hline BnaC03g14740D & A0A0781202 & + & - & -1.16106 & 0.00038 & SPFH/Band 7/PHB domain-containing membrane protein \\
\hline BnaC08g43300D & A0A078GBF1 & - & - & -0.87303 & 0.00190 & Encodes UDP-d-apiose synthase \\
\hline BnaC09g47460D & A0A078G848 & - & + & -1.00000 & 0.00098 & NADH dehydrogenase [ubiquinone] flavoprotein 1 \\
\hline \multicolumn{7}{|c|}{ Anther development protein } \\
\hline BnaA01g13540D & A0A078ICM7 & + & - & -1.88014 & 0.00328 & UDP-glucose 4-epimerase 2 \\
\hline BnaA02g05650D & A0A078F7X9 & - & + & 0.62574 & 0.00412 & Pollen Ole e 1 allergen and extensin family protein \\
\hline BnaA04g21720D & A0A078FVE9 & - & - & -4.52980 & 0.00001 & Type III polyketide synthase A-like \\
\hline BnaA08g15000D & A0A078GE34 & - & - & -6.67917 & 0.00010 & Tetraketide alpha-pyrone reductase 1 -like \\
\hline BnaC07g33620D & A0A078F9K9 & + & - & 0.83443 & 0.06855 & Pollen-specific leucine-rich repeat extension-like protein 1 \\
\hline BnaA04g26600D & A0A078HGU6 & + & - & -1.34373 & 0.00096 & LDL receptor wingless signaling/trafficking chaperone \\
\hline \multicolumn{7}{|c|}{ Energy transport-related protein } \\
\hline BnaA03g01500D & A0A078FEE1 & - & - & -1.18473 & 0.00094 & Lysosomal beta glucosidase-like \\
\hline BnaA10g11120D & A0A078HLN1 & - & - & -1.42526 & 0.00070 & Calcium-transporting ATPase \\
\hline BnaC01g21970D & A0A078H9K8 & - & - & -0.64160 & 0.04709 & Dihydrolipoyl dehydrogenase \\
\hline BnaC06g00540D & A0A078IEJ9 & - & - & 2.38727 & 0.00002 & Probable mitochondrial chaperone BCS1-B \\
\hline BnaCnng66500D & A0A078JT79 & - & - & 0.88088 & 0.00126 & ATP synthase subunit delta, chloroplastic-like \\
\hline \multicolumn{7}{|c|}{ Tapetum development protein } \\
\hline BnaA01g23670D & A0A078FYQ2 & + & - & -3.60823 & 0.00012 & May play a role in tapetum development. \\
\hline BnaA09g 10680D & A0A078HQA1 & + & - & -5.68514 & 0.00001 & 4-Coumarate-CoA ligase-like 1 \\
\hline \multicolumn{7}{|c|}{ Oxidative phosphorylation protein } \\
\hline BnaA01g17520D & A0A078H3Z4 & - & + & -2.71786 & 0.00052 & Peroxidase \\
\hline BnaC01g19630D & A0A078GUT8 & - & - & 1.71357 & 0.00002 & NADPH-protochlorophyllide oxidoreductase \\
\hline
\end{tabular}

gluconeogenesis pathways is considerably diverse. Our findings refer that energy changes should be fundamental in pol CMS. Using the yeast two-hybrid system, we discovered the restorer gene, and it was found that the protein involved in RNA editing may work together in the pol CMS atp6/orf224 transcript [29]. Furthermore, sharing caused the infertility gene to be non-functional.

The pol CMS restorer gene $R f p$ encodes a PPR protein that usually recognizes and binds to RNA sequences in organelles [39]. In a previous study of pol CMS, the materials of sterile, maintainer, and restorer lines were compared with northern blotting, and the results showed that the original atp6/orf 224 was transcribed into $1.1 \mathrm{~kb}$,
$2.2 \mathrm{~kb}$, and $1.9 \mathrm{~kb}$ transcripts relative to the sterile and restorer lines, respectively. However, in the reintroduction line materials, two transcripts of $2.2 \mathrm{~kb}$ and $1.9 \mathrm{~kb}$ were significantly reduced, whereas two new transcripts of $1.4 \mathrm{~kb}$ and $1.3 \mathrm{~kb}$ appeared simultaneously [41]. Therefore, we presumed that pol CMS's restoration gene participated in the editing of atp6/orf 224 mRNA. The transcript of atp6/orf 224 translates the orf 224 protein, and orf 224 has been found to exert a toxic effect on Escherichia coli.

Moreover, orf 288 has a toxic protein function in hau CMS, which leads to male sterility [2]. In the present study, we located three RNA editing-related proteins. 


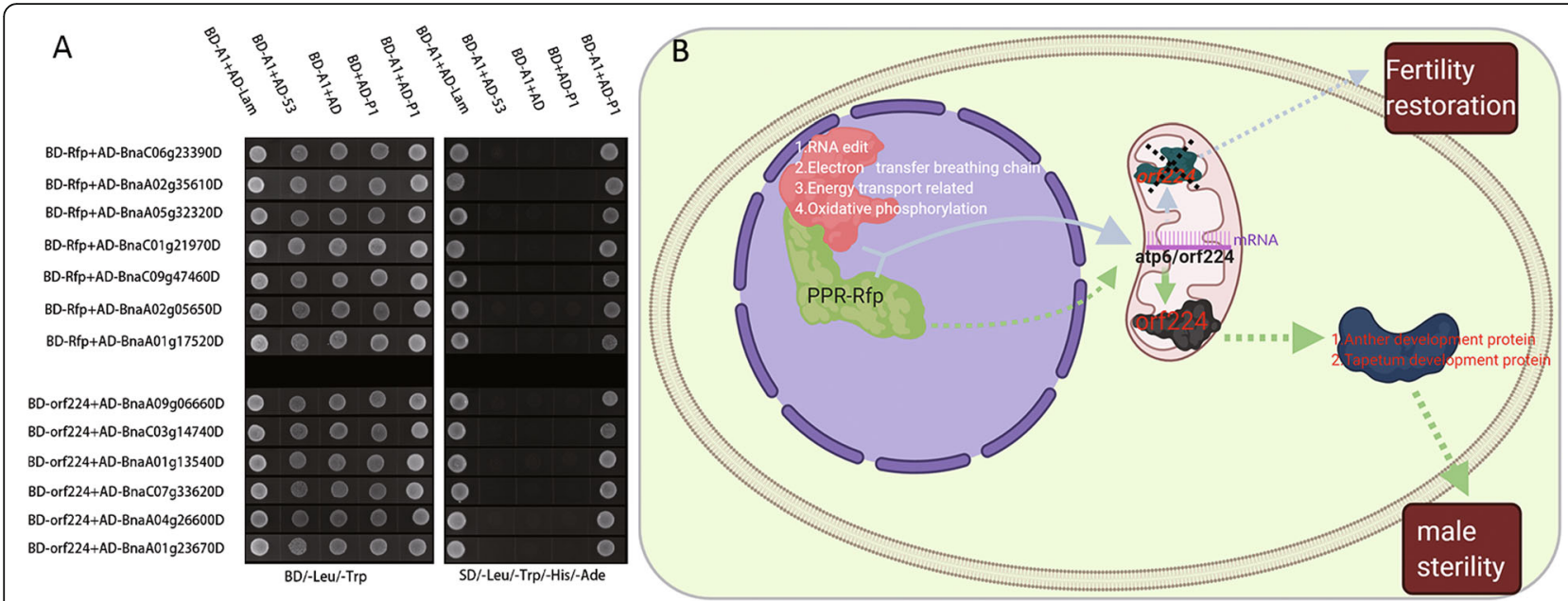

Fig. 7 A Possible Mechanism Contributing to the Occurrence of Sterility and Recovery of Fertility in Pol CMS Lines of B. napus. a Multi-omics association analysis of candidate genes using yeast to screen for related genes. b A proposed a pol CMS working model showing the pol CMS mechanism and infertility mechanism of Rfp and orf224

Verification by yeast revealed that two proteins that interacted with restorer genes and one protein that interacted with sterile genes might be involved in cutting the pol CMS sterile gene atp6/orf224 transcript (Fig. 7b).

Studies have found that CMS genes are mainly composed of mitochondrial genes, and mitochondria serve as the primary energy supplier in living organisms [[42, 43]]. The vast majority of CMS genes are chimeric genes generated by mitochondrial arrangement events, in which cox 1, atp 8, and atp6 function as infertility genes; however, most of them encode electron transport respiratory chain-related proteins or ATP synthase related complexes [14, 44]. Co-transcription and the electron transport chain's normal metabolism is closely related to energy metabolism [45]. It is believed that in maize TCMS, T-URF13 causes unrecoverable damage near the MT membrane, leading to the loss of membrane potential and, ultimately, mitochondrial breakdown and sterility $[[10,46]]$. In the rapeseed ogu CMS, the infertility gene orf138 was found to disrupt the electron transport chain inside the mitochondrial membrane, leading to anthers abortive [47].

In the phenomenon of cytoplasmic male sterility in higher plants, mitochondrial gene mutations lead to infertility. Several crop studies have found that both early and delayed degradation of tapetum cells can lead to infertility. As a staged tissue, the tapetum provides nutrients and energy for the maturation of microspore cells. In the omics studies of Chinese cabbage [47], salvia [48], rape [49], watermelon [50], and cotton [51], it has been found that the glycolysis/gluconeogenesis pathway has an essential function in the process of male sterility. Because the glycolysis/ gluconeogenesis pathway produces many carbohydrates and various enzymes, it is closely related to plants' average growth and development. However, due to male sterility's complex regulatory factors, this type of gene has not been verified by molecular biology for its specific effect on male sterility. However, through additional crop omics testing and analysis, the glycolysis/gluconeogenesis pathway is closely related to male sterility.

Similarly, the electron transport respiratory chain disorder and disrupted ATP synthase complex function have been found in the Petunia CMS Connett, wild G-CMS beets [42], and sunflower CMS [52]. These previous findings showed an association between the CMS protein and the mitochondrial electron transport chain complex. For example, in rice CMS lines, the sterility genes orf79 and orfH79 caused decreased ATP/ADP ratio and increased reactive oxygen species in anthers [15]. We found that the rapid division of mitochondrial genes during anther development may lead to mitochondrial function defects, leading to insufficient energy supply for male organ development and triggering abortion [52]. All the above information indicates that extreme energy insufficiency in mitochondria is the only possible cause of CMS, but the mechanism that triggers unfunctional pollen is still not entirely understood [53]. Researchers cogitated that the CMS protein binds to specific mitochondrial proteins in some way to achieve this effect, but no relevant candidate proteins have been found. Among our differential candidate genes, we also found electron transfer chain-related proteins and energy transfer-related proteins that interact with restorer genes, which may cause CMS 
and restorer of fertility [54]; however, further research and more scientific evidence are needed to confirm the current hypothesis.

We used stereomicroscopy and scanning electron microscopy to observe the differences in anther and pollen development in sterile and fertile lines of B. napus. The results showed that the pollen grains of sterile plants markedly shrank, bent inward, and collapsed, whereas those of fertile plants showed a normal phenotype [55]. In our research, using transmission electron microscopy analysis of semi-thin sections, we observed that pol CMS's sterile line material exhibited abnormalities and disintegration. These abnormalities mostly occurred in the third phase of anther development and led to early PCD of sporogenous cells, which eventually led to the abnormal differentiation of L2 cells, outer cells, inner cells, tapetum cells, and microspore mother cells [54, 56, 57]. In this study, we identified many anther development-related proteins and tapetum development-related proteins in sterile plants, and these proteins were associated with sterility genes. Thus, we concluded that pol CMS's sterility genes caused the production of abnormal anther and tapetum development-related proteins, which led to anther abortion [31]. However, there are also significant shortcomings in this project. Although several candidate genes were screened by combined multi-omics analysis and yeast two-hybrid experiments, the corresponding results were not verified by other molecular biology experiments and oil-seed rape transgenesis.

\section{Conclusions}

In the combined analysis of pol CMS's near-isogenic lines with multiple omics, we screened 24 differential genes and carried out yeast two-hybrid detection of these differential genes with the restorer gene $R f p$ sterility gene orf 224 in pol CMS, looking for the same pol CMS fertility changes related protein. Finally, we screened seven $R f p$ interacting proteins, whose primary functions are RNA editing, anther development, and tapetum development-related protein interactions. The sterility gene orf 224 protein screened out five interacting proteins; their main functions are electronic the respiratory transmission chain, anther development, and oxidative phosphorylation related proteins. Therefore, we speculate that the restorer gene $R f p$ acts on the sterility gene by forming a protein complex with the above types of proteins, resulting in the loss of function of the sterility gene and the restoration of fertility. Infertility genes mainly interact with proteins related to the electron respiratory transport chain, directly act on proteins related to anther development, or interact with proteins related to oxidative phosphorylation, which affect the development of anthers and fail to develop pollen grains that are initially normal. Therefore, we have screened 12 candidate genes through multi-omics joint analysis combined infertility genes and restorer genes for follow-up research, which provides a specific data basis for the analysis of pol CMS, and also provides help for revealing the potential molecular mechanism of pol CMS.

\section{Methods \\ Sample collection}

In the laboratory, bing409 (pol restorer line)(Source: Prof. Tingdong $\mathrm{Fu}$ ) and 1141A (sterile pol line)(Source: Prof. Tingdong $\mathrm{Fu}$ ) was used to establish a near-isogenic line (NIL) through 13 generations of backcrossing (Source: Dr. Zonghui Yang). Using this material, we finely mapped the pol CMS restorer gene. In the BC8 generation, the $32 \mathrm{~kb}$ infiltrated the specific marker scanning located gene fragment, and then the experiment was carried out by crossing 13 generations of sterile lines and reproductive lines. The NIL of oil-seed rape was seeded in May 2018 in Wuhan, with the seedling density controlled to $20 \mathrm{~cm} \times 40 \mathrm{~cm}$. The NIL material passed the multi-year backcrossing experiment, and the phenotype was 1:1 sterile line to the restorer line. The sterile and fertile phenotypes can be well distinguished. Through paraffin section observation, we found that the infertility period of pol CMS was 3-4 stages of anther development, and the degradation of tapetum occurred in advance, leading to abortion [29]. In stages 2-3 of anther development, the flower buds' size was $<1 \mathrm{~mm}$; therefore, we collected flower buds of $<1 \mathrm{~mm}$ and studied the proteome and metabolome. All samples taken were frozen in liquid nitrogen and stored at $-80^{\circ} \mathrm{C}$. Simultaneously, we collected the flower buds of sterile and fertile lines in the same period and fixed them for laser microdissection capture to study single-cell transcriptomics. This procedure was conducted to investigate pol CMS more accurately at the metabolic, protein, and transcription levels. The transcriptome, proteome, and metabolome sample collection set up three biological replicates for omics sequencing analysis.

\section{Metabolite extraction and processing}

The sample preparation and metabolite extraction procedures were as follows: $100 \pm 1 \mathrm{mg}$ of 3-4-stage anther was put in a $2 \mathrm{~mL}$ EP tube, and $0.6 \mathrm{~mL}$ extraction buffer $\left(\mathrm{V}_{\text {methanol }}: \mathrm{V}_{\mathrm{dH} 2 \mathrm{O}}=3: 1\right)$ was added, followed by $20 \mu \mathrm{L}$ of adonitol $\left(1 \mathrm{mg} / \mathrm{mL}\right.$ stock in $\left.\mathrm{dH}_{2} \mathrm{O}\right)$ as per the internal standard. The column used was Waters ACQUITY UPLC HSS T3 C18 $(1.8 \mu \mathrm{m}, 2.1 \mathrm{~mm} \times 100 \mathrm{~mm}$. The mobile phase used was as follows: Phase A, ultrapure water (containing $0.04 \%$ acetic acid); Phase B, acetonitrile (containing $0.04 \%$ acetic acid). The elution gradient program was as follows: $0.00-10.00 \mathrm{~min} 0 \% \mathrm{~B} ; 10.00-11.00$ $\min 95 \% \mathrm{~B} ; 11.00-11.10 \mathrm{~min}, 5 \% \mathrm{~B} ; 11.10-14 \mathrm{~min}$, maintained at 5\% B." At $10.00 \mathrm{~min}$, B's ratio increased linearly 
to $95 \%$ and remained at $95 \%$ for $1 \mathrm{~min}$. From 11.00 to $11.10 \mathrm{~min}, \mathrm{~B}$ 's ratio decreased to $5 \%$ and maintained till $14 \mathrm{~min}$. The elution conditions were as follows: The flow rate is $0.35 \mathrm{~mL} / \mathrm{min}$; the column temperature is $40{ }^{\circ} \mathrm{C}$; the injection volume is $4 \mu \mathrm{L}$. The mass spectrometry conditions are as follows: the electrospray ionization temperature is $550^{\circ} \mathrm{C}$; the electrospray ionization temperature is $550^{\circ} \mathrm{C}$. Mass spectrometer voltage, 5500 $\mathrm{V}$; curtain gas $30 \mathrm{psi}$; collision induced dissociation parameters [58]. Each ion pair is scanned based on the best intersecting potential and collision energy in the triple quadrupole for detection. Metabolic profiling is performed using a broad range of targeted metabolomic approaches at Wuhan Metware Biotechnology [59]. (Wuhan, China) (http://www.metware.cn/).

\section{Lab-free method for proteome detection}

The anther was first ground in liquid nitrogen. The powder was transferred to a $5 \mathrm{~mL}$ centrifuge tube and sonicated three times on ice using a high-intensity ultrasonic processor (Sanchez-Puerto et al., 2015) in lysis buffer (containing 1\% TritonX-100, $10 \mathrm{mM}$ dithiothreitol, 1\% protease inhibitor cocktail, $50 \mu \mathrm{M}$ PR-619, $3 \mu \mathrm{M}$ TSA, $50 \mathrm{mM}$ NAM, and $2 \mathrm{mM}$ EDTA). Equal volume of trisaturated phenol (ph 8.0) was added, and then the mixture was further rotated for $5 \mathrm{~min}$. After centrifugation $\left(4^{\circ} \mathrm{C}\right.$, $10 \mathrm{~min}, 5000 \times \mathrm{g}$ ), the upper phenol phase was transferred to a new centrifuge tube. Proteins were precipitated by adding at least four volumes of ammonium sulfatesaturated methanol, followed by incubation at $-20{ }^{\circ} \mathrm{C}$ for at least $6 \mathrm{~h}$. After centrifugation at $4{ }^{\circ} \mathrm{C}$ for $10 \mathrm{~min}$, the supernatant was discarded. The remaining precipitate was washed once with ice-cold methanol and then with ice-cold acetone three times. Re-dissolve the protein in $8 \mathrm{M}$ urea and use the BCA kit to determine the protein concentration according to the manufacturer's instructions.

The trypsin peptide was dissolved in $0.1 \%$ formic acid (solvent a) and directly loaded on a self-made reversedphase analytical column (length: $15 \mathrm{~cm}, 75 \mu \mathrm{m}$ ). The gradient consisted of increasing from $6 \% \mathrm{~B}$ to $23 \%$ solvent B ( $0.1 \%$ formic acid in $98 \%$ acetonitrile) in $26 \mathrm{~min}$, from 23 to $35 \%$ in $8 \mathrm{~min}$, climbing to $80 \%$ in $3 \mathrm{~min}$, and then remaining at $80 \%$ on easy-nlc 1000 UPLC system. The flow rate was $400 \mathrm{nl} / \mathrm{min}$ in the last $3 \mathrm{~min}$. The peptides were processed from NSI sources, and then tandem mass spectrometry (MS/MS) was performed in Q ExactiveTM Plus (Thermo) connected online to UPLC. The applied electrospray voltage was $2.0 \mathrm{kV}$. The $\mathrm{m} / \mathrm{z}$ scan range of the complete scan is 350 to 1800 , and the complete peptide is detected in Orbitrap with a resolution of 70,000. Then use NCE to set 28 to select peptides for MS/MS, and detect these fragments in Orbitrap with a resolution of 17,500 . The data-dependent process performs $20 \mathrm{MS} / \mathrm{MS}$ scans after one MS scan, and the dynamic elimination time is $15.0 \mathrm{~s}$. Automatic gain control (AGC) is set to 5E4. The fixed first mass setting is $100 \mathrm{~m} / \mathrm{z}[60]$.

The corresponding signal abundance of the protein in each sample is detected by mass spectrometry technology. The LFQ intensity of the protein in each sample is obtained by the non-standard quantitative calculation method, and the relative quantitative value of each sample is obtained according to the protein LFQ intensity between different samples. The first step is to calculate the protein's differential expression between the two samples in the comparison group. First, calculate the average of each sample's quantitative value in multiple replicates, and then calculate the ratio of the average between the two samples, which is taken as the final differential expression of the comparison group. The second step is to calculate the significance $P$-value of the protein's differential expression in the two samples. First, take the relative quantitative value of each sample to $\log 2$ (to make the data conform to the normal distribution), and then use the two-sample two-tailed T-test method to calculate a $p$-value. When $p$-value $<0.05$, the change of differential expression exceeding 1.5 is used as the change threshold for significant up-regulation, and the change threshold for significant down-regulation is less than $1 / 1.5$.

Gene was classified by Gene Ontology annotation into three categories: biological process, cellular compartment, and molecular function. The GO with a corrected $p$ value of $<0.05$ is considered important [61]. The Encyclopedia of Genes and Genomes (KEGG) database is used to identify enrichment pathways through twotailed Fisher's exact test to test the enrichment of all identified proteins by differentially expressed proteins [62]. Paths with corrected $p$-value $<0.05$ are considered important.

\section{Single-cell transcriptome sequencing using microdissection}

Laser microdissection technology was used to separate single cells or organelles from tissue sections by laser cutting. The operator observed a tissue slice under a microscope, located the target cell, marked the target cell area on the computer display screen, and then cut the region with the laser to extract it [52].

First, the flower bud sections were treated with 75, 85, and $95 \%$ alcohol in a water bath of $58{ }^{\circ} \mathrm{C}$ each for $90 \mathrm{~s}$ each, followed by n-butanol and absolute ethanol at varying ratios $1: 1$ and $3: 1$ at $58^{\circ} \mathrm{C}$ twice for $90 \mathrm{~s}$ each. Finally, the pre-embedding treatment of the micro-cut material was completed by treatment with $\mathrm{n}$-butanol at $58^{\circ} \mathrm{C}$ for $90 \mathrm{~s}$. Subsequently, the sample was immersed in paraffin at $65^{\circ} \mathrm{C}$ three times for $30 \mathrm{~min}, 60 \mathrm{~min}$, and 
90 min each, and then embedded in an embedding box. Slides with glass slide membrane were treated with RNase and 75\% alcohol. The thickness of the sections was selected according to the depth of the treated material. The flower bud width was sliced $16 \mu \mathrm{m}$.

The single-cell samples were collected in tubes containing lysis components and ribonuclease inhibitors. Amplification was then performed by using the SmartSeq2 method [63]. An Oligo-dT primer was introduced to the reverse transcription reaction for first-strand cDNA synthesis, followed by PCR amplification to enrich the cDNA and a magnetic bead purification step to clean up the synthesized material. Next, the cDNA product was checked by a Qubit ${ }^{\circ}$ 3.0 Fluorometer and Agilent 2100 Bioanalyzer (Thermo Fisher Scientific) to ensure the expected output of length approximately 1-2 kbp. Subsequently, cDNA was sheared randomly by ultrasonic waves for Illumina library preparation, including DNA fragmentation, end-repair, 3' end A-tailing, adapter ligation, PCR amplification, and library validation. PerkinElmer LabChip ${ }^{\circ}$ GX Touch and Step OnePlus $^{\text {Tu }}$ Real-Time PCR System were introduced for library quality inspection after library preparation. Qualified libraries were then loaded on the Illumina Hiseq platform for PE150 sequencing.

\section{Yeast two-hybrid assay}

The full-length cDNAs of the recovery gene $R f p$ and the sterility gene orf 224 were amplified and cloned into the bait vector pGBKT7, while the candidate genes were cloned into the prey vector pGADT7, respectively. The vectors constructed by bait vector pGBKT7 and prey vector pGADT7 were then co-transformed into yeast strain AH109 receptor cells [64].

\section{RNA extraction, reverse transcription PCR}

Referring to the reagent manufacturer's instructions, we extracted total RNA from kale type oilseed rape using Trizol reagent (Invitrogen), resuspended the RNA in RNase-free water, and treated it with RNasefree DNase I (Thermo Fermentas). After digestion treatment with DNase I, PCR amplification was used to confirm the elimination of DNA contamination. We then reverse transcribed the digested RNA using M-MLV reverse transcriptase (Invitrogen) and random primers (Thermo Fermentas) to obtain cDNA. cDNA was amplified on a Light Cycler 480 (Roche) using SYBR Green I with gene-specific primers. Real-time quantitative PCR was performed on a Light Cycler 480 (Roche) using a SYBR Green I Master PCR kit with gene-specific primers to detect the expression of kale type oilseed rape genes [65].

\section{Supplementary Information}

The online version contains supplementary material available at https://doi. org/10.1186/s12870-021-02852-7.

Additional file 1: Figure S1. Metabolome heat map and KEGG enrichment analysis statistical map (A) Heat map of clustering of significant metabolites of sterile lines and restore lines of near-isogenic lines. (B) Analysis of KEGG enrichment of significant metabolites

Additional file 2: Figure S2. Proteome analysis of pol CMS nearisogenic lines and sterile lines. (A) Basic statistical graph of proteome mass spectrometry data results. (B) PCA analysis of sterile proteome line and restore line material. (C) Proteome mass spectrometry analysis of the overall peptides. (D) Differentially expressed proteins

Additional file 3: Figure S3. Quality summary of single-cell transcriptome original sequencing data

Additional file 4: Figure S4. (A) Single-cell transcriptome Venn diagram shows the expression of genes between samples. (B) Proteome and metabolome combined analysis with KEGG enrichment analysis. (C) Proteome and transcriptome joint analysis with KEGG enrichment analysis. (D) Combined analysis of transcriptome and metabolome with KEGG enrichment

Additional file 5: Figure S5. RT-PCR was used to detect candidate genes' relative expression levels in pol CMS sterile 6330A and restorer lines

Additional file 6: Table S1. Significantly different metabolites of the metabolome

Additional file 7: Table S2. Significantly different genes of transcription Additional file 8: Table S3. Significantly different proteins of proteome Additional file 9: Table S4. Enrichment analysis of KEGG metabolites Additional file 10: Table S5. Proteomic Differential Protein KEGG Enrichment Analysis

Additional file 11: Table S6. Transcriptome differential gene KEGG enrichment analysis

\section{Abbreviations}

PPR: Pentatricopeptide Repeat; CMS: Cytoplasmic male sterility; PCD: Programmed cell death; GO: Gene Ontology; KEGG: The Encyclopedia of Genes and Genomes; PCA: Principal component analysis; DAPs: Differentially abundant proteins; DEGs: Differentially expressed genes; ESP: Epithiospecifier protein

\section{Acknowledgments}

We thank professor Xuelu Wang and professor Chunmei Shi for help with laser fiber cutting; PTM bio (https://www.ptmbiolabs.com/) for help with the proteome, Wuhan Metware Biotechnology (https://www.metware.cn/) for help with the metabolome, and Anogene (http://www.genome.cn/) for help with the single-cell transcriptome. Thanks to Dr. Kaining Hu for his help with bioinformatic analysis. We would like to thank Editage (www.editage.cn) for English language editing.

\section{Authors' contributions}

ZF helped with article revision and RNA extraction, $C L$ helped with sampling and yeast two-hybrid experiments, LJ, WH, and GJ contributed to the design of the work, the acquisition, analysis, and interpretation of data; Prof. TF, Dr. ZY. Provide seeds for experimental material, JT., CM., CD., JW., and JS. Provided a flexible research platform and environment, and BY., he conceived and designed the experiments. All authors have read and approved the manuscript.

\section{Funding}

This project was supported by National Key Research and Development Program of China (2016YFD0100804) and National Natural Science Foundation of China supported this project (Grant No. 31871701, 31930032). Funding agencies had no role in the study design, data collection, analysis, or data interpretation. 


\section{Availability of data and materials}

The original transcriptome sequencing data related to this article is stored in the NCBI SRA database with the Submission ID SUB8446872 (https:/submit. ncbi.nlm.nih.gov/subs/bioproject/) and the BioProject ID PRJNA673655(https:// www.ncbi.nlm.nih.gov/sra/PRJNA673655), Reviewer link: https://dataview.ncbi. nlm.nih.gov/object/PRJNA673655? reviewer=5lfitb644f2dg76db7tat7pwh . Other data from the results of this article are also included in this article and its attached files.

\section{Ethics approval and consent to participate}

Not applicable.

\section{Consent for publication}

Not applicable.

\section{Competing interests}

The authors declare that they have no conflict of interest.

\section{Received: 17 August 2020 Accepted: 24 January 2021}

Published online: 05 March 2021

\section{References}

1. Eckardt NA. Cytoplasmic male sterility and fertility restoration. Plant Cell. 2006;18:515-7.

2. Heng S, Gao J, Wei C, Chen F, Li X, Wen J, et al. Transcript levels of orf288 are associated with the hau cytoplasmic male sterility system and altered nuclear gene expression in Brassica juncea. J Exp Bot. 2018;69:455-66.

3. Chase CD, Gabay-Laughnan S. Cytoplasmic Male Sterility and Fertility Restoration by Nuclear Genes BT- Molecular Biology and Biotechnology of Plant Organelles: Chloroplasts and mitochondria. 2004. p. 593-621.

4. Chase CD. Cytoplasmic male sterility: a window to the world of plant mitochondrial-nuclear interactions. Trends Genet. 2007:23:81-90.

5. Hanson MR, Bentolila S. Interactions of mitochondrial and nuclear genes that affect male gametophyte development. Plant Cell. 2004;16 Suppl Suppl: S154-S169.

6. Mackenzie S. 12 - Male sterility and hybrid seed production. 2012. p. 185-194

7. Chen L, Liu Y-G. Male sterility and fertility restoration in crops. Annu Rev Plant Biol. 2013;65.

8. Wang Z, Zou Y, Li X, Zhang Q, Chen L, Wu H, et al. Cytoplasmic Male Sterility of Rice with Boro II Cytoplasm Is Caused by a Cytotoxic Peptide and Is Restored by Two Related PPR Motif Genes via Distinct Modes of mRNA Silencing. Plant Cell. 2006;18:676 LP - 687.

9. Jing B, Heng S, Tong D, Wan Z, Fu T, Tu J, et al. A male sterility-associated cytotoxic protein ORF288 in Brassica juncea causes aborted pollen development. J Exp Bot. 2012:63.

10. Korth KL, Kaspi Cl, Siedow JN, Levings CS 3rd. URF13, a maize mitochondrial pore-forming protein, is oligomeric and has a mixed orientation in Escherichia coli plasma membranes. Proc Natl Acad Sci U S A. 1991;88: 10865-9.

11. Luo D, Xu H, Liu Z, Guo J, Li H, Chen L, et al. A detrimental mitochondrialnuclear interaction causes cytoplasmic male sterility in rice. Nat Genet. 2013;45.

12. Lee SJ, Warmke HE. Organelle size and number in fertile and T-cytoplasmic male-sterile corn. Am J Bot. 1979;66:141-8.

13. Logan DC. The mitochondrial compartment. J Exp Bot. 2006:57:1225-43.

14. Rhoads DM, Levings CS 3rd, Siedow JN. URF13, a ligand-gated, poreforming receptor for T-toxin in the inner membrane of $\mathrm{cms}$-T mitochondria. J Bioenerg Biomembr. 1995;27:437-45.

15. Peng $X$, Wang $K$, Hu C, Zhu Y, Wang T, Yang J, et al. The mitochondrial gene orfH79 plays a critical role in impairing both male gametophyte development and root growth in CMS-Honglian rice. BMC Plant Biol. 2010; 10:125.

16. Wang K, Gao F, Ji Y, Liu Y, Dan Z, Yang P, et al. ORFH79 impairs mitochondrial function via interaction with a subunit of electron transport chain complex III in Honglian cytoplasmic male sterile rice. New Phytol. 2013:198:408-18.

17. Ogura H. Studies on the new male-sterility in Japanese radish, with specia reference to the utilization of this sterility towerds the practical raising of hybrid seeds. 1967

18. Thompson KF. Cytoplasmic male-sterility in oil-seed rape. Heredity (Edinb). 1972:29:253-7
19. Banga SS, Labana KS, Banga SK. Male sterility in Indian mustard (Brassica juncea L.) Coss a biochemical characterization. Theor Appl Genet. 1984;67: 515-9.

20. Hu Q, Hua W, Yin Y, Zhang X, Liu L, Shi J, et al. Rapeseed research and production in China. Crop J. 2016:5

21. Liu J, Li M, Wang H, Yu L, Li D. Sequence analysis and expression of orf224 gene associated with two types of cytoplasmic male sterility in Brassica napus L. Z Naturforsch C. 2010;65:395-402.

22. Heng S, Wei C, Jing B, Wan Z, Wen J, Yi B, et al. Comparative analysis of mitochondrial genomes between the hau cytoplasmic male sterility (CMS) line and its iso-nuclear maintainer line in Brassica juncea to reveal the origin of the CMS-associated gene orf288. BMC Genomics. 2014;15:322.

23. Liu J, Xiang R, Wang W, Mei D, Li Y, Mason A, et al. Cytological and molecular analysis of Nsa CMS in Brassica napus L. Euphytica. 2015:206.

24. Hu Q, Andersen S, Dixelius C, Hansen L. Production of fertile intergeneric somatic hybrids between Brassica napus and Sinapis arvensis for the enrichment of the rapeseed gene pool. Plant Cell Rep. 2002;21:147-52.

25. Li P, Kang L, Wang A, Cui C, Jiang L, Guo S, et al. Development of a fertility restorer for inap CMS (Isatis indigotica) Brassica napus through genetic introgression of one alien addition. Front Plant Sci. 2019:10.

26. L'Homme Y, Stahl RJ, Li X-Q, Hameed A, Brown GG. Brassica napus cytoplasmic male sterility is associated with expression of a mtDNA region containing a chimeric gene similar to the pol CMS-associated orf224 gene. Curr Genet. 1997;31:325-35.

27. Wei W, Wang H, Liu G. Transcriptional regulation of 10 mitochondrial genes in different tissues of NCa CMS system in Brassica napus L. and their relationship with sterility. J Genet Genomics. 2007;34:72-80.

28. Handa H, Gualberto JM, Grienenberger J-M. Characterization of the mitochondrial orfB gene and its derivative, orf224, a chimeric open reading frame specific to one mitochondrial genome of the "Polima" male-sterile cytoplasm in rapeseed (Brassica napus L.). Curr Genet. 1995;28:546-52.

29. Liu Z, Yang Z, Wang X, Li K, An H, Liu J, et al. A Mitochondria-Targeted PPR Protein Restores pol Cytoplasmic Male Sterility by Reducing orf224 Transcript Levels in Oilseed Rape. Mol Plant. 9:1082-4.

30. Liu Z, Liu P, Long F, Hong D, He Q, Yang G. Fine mapping and candidate gene analysis of the nuclear restorer gene $R f p$ for pol CMS in rapeseed (Brassica napus L.). Theor Appl Genet. 2012;125:773-9.

31. Liu Z, Dong F, Wang X, Wang T, Su R, Hong D, et al. A pentatricopeptide repeat protein restores nap cytoplasmic male sterility in Brassica napus. J Exp Bot. 2017:68:4115-23.

32. Sheoran I, Sawhney V. Proteome analysis of the normal and Ogura (ogu) CMS anthers of Brassica napus to identify proteins associated with male sterility. Botany. 2010;88:217-30.

33. An H, Yang Z, Yi B, Wen J, Shen J, Tu J, et al. Comparative transcript profiling of the fertile and sterile flower buds of pol CMS in B napus. BMC Genomics. 2014;15:258

34. Rabinowitz JS, Robitaille AM, Wang Y, Ray CA, Thummel R, Gu H, et al. Transcriptomic, proteomic, and metabolomic landscape of positional memory in the caudal fin of zebrafish. Proc Natl Acad Sci U S A. 2017:114: E717-26.

35. Ichihashi $Y$, Date $Y$, Shino A, Shimizu T, Shibata A, Kumaishi $K$, et al. Multiomics analysis on an agroecosystem reveals the significant role of organic nitrogen to increase agricultural crop yield. Proc Natl Acad Sci. 2020;117: 14552 LP - 14560

36. Hwang $B$, Lee $J H$, Bang $D$. Single-cell RNA sequencing technologies and bioinformatics pipelines. Exp Mol Med. 2018;50:96.

37. Zhang D, Yang L. Specification of tapetum and microsporocyte cells within the anther. Curr Opin Plant Biol. 2014;17:49-55.

38. Satoh M, Kubo T, Nishizawa S, Estiati A, Itchoda N, Mikami T. The cytoplasmic male-sterile type and normal type mitochondrial genomes of sugar beet share the same complement of genes of known function but differ in the content of expressed ORFs. Mol Gen Genomics. 2004:272:247-56.

39. Tagliamonte MS, Waugh SG, Prosperi M, Mai V. An integrated approach for efficient multi-Omics joint analysis ACM Conf bioinformatics, Comput biol biomed ACM Conf bioinformatics. Comput Biol Biomed. 2019;2019:619-25.

40. Guasch-Ferré M, Santos JL, Martínez-González MA, Clish CB, Razquin C, Wang D, et al. Glycolysis/gluconeogenesis and tricarboxylic acid cyclerelated metabolites, Mediterranean diet, and type 2 diabetes. Am J Clin Nutr. 2020;111:835-44.

41. L'Homme Y, Stahl RJ, Li XQ Hameed A, Brown GG. Brassica napus cytoplasmic male sterility is associated with expression of a mtDNA region 
containing a chimeric gene similar to the pol CMS-associated orf224 gene. Curr Gen. 1997:31.

42. Ducos E, Touzet P, Boutry M. The male sterile G cytoplasm of wild beet displays modified mitochondrial respiratory complexes. Plant J. 2001;26:171-80.

43. Bergman P, Edqvist J, Farbos I, Glimelius K. Male-sterile tobacco displays abnormal mitochondrial atp 1 transcript accumulation and reduced floral ATP/ADP ratio. Plant Mol Biol. 2000;42:531-44.

44. Arrieta-Montiel M, Mackenzie S. Plant Mitochondrial Genomes and Recombination. In: Advances in Plant Biology: Plant Mitochondria. 2011. p. 65-82.

45. Kubo T, Newton KJ. Angiosperm mitochondrial genomes and mutations. Mitochondrion. 2008;8:5-14.

46. Grelon M, Budar F, Bonhomme S, Pelletier G. Ogura cytoplasmic malesterility (CMS)-associated orf138 is translated into a mitochondrial membrane polypeptide in male-sterile Brassica cybrids. Mol Gen Genet MGG. 1994;243:540-7.

47. Zhou X, Shi F, Zhou L, et al. iTRAQ-based proteomic analysis of fertile and sterile flower buds from a genetic male sterile line 'AB01'in Chinese cabbage Brassica campestris L. ssp. pekinensis. J Proteome. 2019;204:103395.

48. Wang R, Lu C, Shu Z, et al. iTRAQ-based proteomic analysis reveals several key metabolic pathways associated with male sterility in Salvia miltiorrhiza. RSC Adv. 2020;10(29):16959-70

49. Zhiming $\mathrm{S}$, Zhen $\mathrm{W}$, Xiaogian $\mathrm{M}$, et al. A dominant gene for male sterility in Salvia miltiorrhiza Bunge [J]. PLoS One. 2012;7(11):e50903.

50. Heng S, Chen F, Wei C, et al. Cytological and iTRAQ-based quantitative proteomic analyses of hau CMS in Brassica napus L. J Proteome. 2019;193: 230-8.

51. Wang $Y$, Yang $X$, Yadav $V$, et al. Analysis of differentially expressed genes and pathways associated with male sterility lines in watermelon via bulked segregant RNA-seq. 3 Biotech. 2020;10(5):222.

52. Balk J, Leaver CJ. The PET1-CMS mitochondrial mutation in sunflower is associated with premature programmed cell death and cytochrome c release. Plant Cell. 2001;13:1803-18.

53. de BIP, Troxell RM, Graves JS. Mitochondrial Dysfunction and Multiple Sclerosis. Biology (Basel). 2019;8:37. https://doi.org/10.3390/biology8020037.

54. Hu J, Wang K, Huang W, Liu G, Gao Y, Wang J, et al. The rice pentatricopeptide repeat protein RF5 restores fertility in Hong-Lian cytoplasmic male-sterile lines via a complex with the glycine-rich protein GRP162. Plant Cell. 2012;24:109-22.

55. Yuan M, Yang G-S, Fu T-D, Li Y. Transcriptional control of orf224/atp6 by the pol CMS restorer Rfp gene in Brassica napus L. Yi Chuan Xue Bao. 2003;30: 469-73.

56. Streets AM, Zhang X, Cao C, Pang Y, Wu X, Xiong L, et al. Microfluidic single-cell whole-transcriptome sequencing. Proc Natl Acad Sci U S A. 2014; 111:7048-53.

57. Stévant I, Nef S. Single cell transcriptome sequencing: a new approach for the study of mammalian sex determination. Mol Cell Endocrinol. 2018:468:11-8.

58. Wang L, Liang W, Xing J, et al. Dynamics of chloroplast proteome in saltstressed mangrove Kandelia candel (L.) Druce. J Proteome Res. 2013;12(11): 5124-36.

59. Li H, Wu L, Tang N, et al. Analysis of transcriptome and phytohormone profiles reveal novel insight into ginger (Zingiber officinale rose) in response to postharvest dehydration stress. Postharvest Biol Technol. 2020;161: 111087.

60. Wang Z, Yang X, Liu C, Li X, Zhang B, Wang B, Zhang Y, Song C, Zhang T, Liu $\mathrm{M}$, et al. Acetylation of PHF5A modulates stress responses and colorectal carcinogenesis through alternative splicing-mediated Upregulation of KDM3A. Mol Cell. 2019;74(6):1250-63.

61. Chen G, Ye X, Zhang S, et al. Comparative Transcriptome analysis between fertile and CMS flower buds in Wucai (Brassica campestris L.). BMC Genomics. 2018;19:908

62. Zhang $Q, X u$ Y, Huang J, et al. The Rice Pentatricopeptide repeat protein PPR756 is involved in pollen development by affecting multiple RNA editing in mitochondria. Front Plant Sci. 2020:11.

63. Chen P, Liao J, Huang Z, Li R, Zhao Y, Ran S, et al. Comparative proteomics study on anther mitochondria between cytoplasmic male sterility line and its maintainer in Kenaf (Hibiscus cannabinus L.). Crop Sci. 2014;54:1103-14.

64. Sui $X$, Hu Y, Ren $C$, et al. METTL3-mediated $m 6 \mathrm{~A}$ is required for murine oocyte maturation and maternal-to-zygotic transition. Cell cycle (Georgetown, Tex.). 2020;19:1-14.
65. Hu YM, Tang JH, Yang H, Xie HL, Lu XM, Niu JH, et al. Identification and mapping of Rf-I an inhibitor of the Rf5 restorer gene for Cms-C in maize (Zea mays L.). Theor Appl Genet. 2006;113:357-60.

\section{Publisher's Note}

Springer Nature remains neutral with regard to jurisdictional claims in published maps and institutional affiliations.
Ready to submit your research? Choose BMC and benefit from:

- fast, convenient online submission

- thorough peer review by experienced researchers in your field

- rapid publication on acceptance

- support for research data, including large and complex data types

- gold Open Access which fosters wider collaboration and increased citations

- maximum visibility for your research: over $100 \mathrm{M}$ website views per year

At BMC, research is always in progress.

Learn more biomedcentral.com/submissions 